\title{
Reducing the treatment gap for mental, neurological and substance use disorders in Africa: lessons from the Friendship Bench in Zimbabwe
}

\author{
D. Chibanda \\ Department of Psychiatry, University of Zimbabwe, Harare, Zimbabwe
}

\begin{abstract}
Mental, neurological and substance use disorders (MNS) are a leading cause of disability in Africa. In response to the large treatment gap for MNS, a growing body of evidence-based treatments (EBTs) is emerging from Africa; however, there is a dearth of knowledge on how to scale up EBT. The Friendship Bench intervention is a brief psychological treatment delivered through the primary health care system in Zimbabwe by trained lay health workers. It has contributed significantly towards narrowing the treatment gap for common mental disorders in Zimbabwe where it has been scaled up to over 70 primary health care facilities. A three-pronged approach consisting of community engagement, use of EBTs and a government endorsed scale-up plan is described as part of the key strategy leading to the scale up of the Friendship Bench.
\end{abstract}

First published online 12 April 2017

Key words: Mental, neurological and substance use disorders, lay health workers, evidence based treatment.

\section{Background}

Mental neurological and substance use disorders (MNS) contribute significantly to the global burden of disease particularly in low- and middle-income countries (LMICs) (Mokdad et al. 2016) where rates of depression and other common mental disorders are reported to be above $20 \%$ in some primary care settings (Kohn et al. 2004; Chibanda et al. 2014a). Sub-Saharan Africa, with the largest treatment gap for MNS (Sherr et al. 2011; Lund et al. 2015), is compounded by the brain drain of health professionals, and perpetual competing needs for the meagre resources allocated for health (Shidhaye et al. 2015).

Competing needs are often used as justification by governments to allocate $<1 \%$ of the health budgets for MNS care (Gureje \& Alem, 2000). In recent years, a growing body of knowledge is justifying the need to integrate MNS care packages in existing programmes such as those for HIV/AIDS (Collins et al. 2013; Kaaya et al. 2013a; Chibanda et al. 2014a). However, African policymakers remain ill-informed about MNS care and its potential for positive impact on broader socioeconomic and public health issues (Gureje \& Alem, 2000; Ventevogel \& de Jong, 2006; Petersen et al. 2011).

As MNS research continues to grow in sub-Saharan Africa, there is need to strengthen strategies for engaging policymakers (Ventevogel \& de Jong, 2006). Equal

Address for correspondence: D. Chibanda, Department of Psychiatry, University of Zimbabwe, Harare, Zimbabwe.

(Email: dichi@zol.co.zw) attention on how best to leverage existing resources to reduce the treatment gap through evidence-based treatments (EBTs) is also required (Ventevogel \& de Jong, 2006; Ventevogel, 2014; Rahman, 2015, Shidhaye et al. 2015). Zimbabwe, a country struggling with ongoing social-economic challenges, and lacking in human resources for MNS care (12 psychiatrists and 16 psychologists for a population of 13 million), is narrowing this treatment gap by integrating a task-shifting care package - the Friendship Bench.

The Friendship Bench programme is delivered by lay health workers (LHWs) who are trained and supervised by clinical psychologists and psychiatrists in the country's primary care facilities. Running since 2006 (Chibanda et al. 2011), the Friendship Bench has recently been scaled up to over 70 primary health care clinics following a successful clinical trial (Chibanda et al. 2015a). The brief psychological intervention delivered through the Friendship Bench is based on problem-solving therapy (PST) with components of activity scheduling and behaviour activation. Key elements include kuvhura pfungwa (opening of the mind), kusimudzira (uplifting) and kusimbisa (strengthening) (Chibanda et al. 2015a).

A three-pronged approach consisting of: (i) community engagement, (ii) EBT approaches and (iii) a government endorsed scale-up strategy leading to the scale up is described.

\section{Community engagement}

Community engagement is an interactive process that brings together community members, researchers and 
other key stakeholders, as equal partners in initiatives that benefit the community. Several overlapping strategies including, formative research, community and traditional leaders' support, partnership with community stakeholders, community sensitisation and education have been identified as critical for community engagement (Musesengwa \& Chimbari, 2016). It has been argued that while these strategies are essential, they often prioritise communication aimed at defending science from misinformation and seek to educate the community about science, with less emphasis on building trust and establishing resonance with the public (Dudo \& Besley, 2016). This often results in communities not driving the public health agenda (South \& Phillips, 2014).

In recent years, an engagement strategy that has gained considerable traction and appears to address all the above issues while fostering genuine collective team building between communities, user groups and researchers is the theory of change (ToC) approach (De Silva et al. 2014). The ToC approach facilitates stakeholder participation, including communities through a collective iterative process, which enables explicit identification of causal pathways, and potential for linking indicators to the design of interventions (Hailemariam et al. 2015; Breuer et al. 2016). For instance, engaging key stakeholders in participatory planning of mental health services through ToC workshops has been effective in India, South Africa, Nepal, Uganda and Ethiopia through the Programme for Improving Mental Health Care (PRIME) (Hailemariam et al. 2015).

A component not often addressed in ToC workshops is that of scaling up interventions, particularly in the absence of funding.

In Zimbabwe, a deliberate focus on the subject of scale-up post-funding has been included in ToC workshops related to the development of a local intervention - The Friendship Bench (Chibanda et al. 2011). After successfully engaging both local and international stakeholders through a series of ToC workshops (Chibanda et al. 2016c), a separate component specifically aimed at exploring the feasibility of scale up was undertaken with the involvement of the community (Chibanda et al. 2016d). Through this scale-up strategy a range of requirements were put forward with specifics on how to address each of them. These included a thorough needs assessment involving key stakeholders and community members, and identifying key priority areas. Other requirements included skills assessment to identify core competencies and current gaps of LHWs, nurses and doctors and consultations to determine funding mechanisms both locally and externally. Our final ToC narrative described key requirements for scale-up, which included early buy-in from key stakeholders particularly the community. Emphasis was placed on the use of existing human resources, obtaining financial support locally, and developing a coherent sustainability plan endorsed by the public, government and private sector (Chibanda et al. 2016d). A particularly powerful component of the ToC approach that seemed to unify participants and contribute towards building consensus for scale-up was the creation of the ToC map, which provided a visual illustration of the causal pathway leading to scale-up. The ToC map further illustrated expected benefits for the community as a result of the scale-up. Community members and LHW described the ToC map as an effective visual tool for building consensus on an evidence-based intervention (Chibanda et al. 2016c).

\section{EBT approach}

Treatment packages for MNS adapted from the West have been effective in several clinical trials conducted in Africa (Mynors-Wallis et al. 1995; Cooper et al. 2002b; Bolton et al. 2003; Kaaya et al. 2013b; Nakimuli-Mpungu et al. 2013; Chibanda et al. 2014b); however, translation of results into routine practice and scale up has been a challenge (Olagunju et al. 2013; Shidhaye et al. 2015). Clinical trials often do not reflect the real world, particularly in relation to human resources and financial realities on the ground. For instance, interventions in clinical trial settings are often delivered by skilled cadres such as psychologists, Ph.D. candidates, nurses and doctors (Chibanda et al. 2015b; Verhey et al. 2016), and are usually well funded. Furthermore, ensuring fidelity outside of a clinical trial setting particularly where LHWs are the delivering agent can be challenging.

Translating EBT into local context should therefore take into consideration existing human resources such as LHWs (Patel et al. 2010). Although requiring more training and supervision, LHWs can offer sustainable options through task shifting (Ventevogel, 2014) and there is growing evidence supporting the use of this cadre (Cooper et al. 2002a; Chibanda et al. 2011; van't Hof et al. 2011; van Ginneken et al. 2013; Nakimuli-Mpungu et al. 2015). LHWs often understand the local context and can facilitate a balanced mix between emic and etic features (Patel \& Mann, 1997) or cross-cultural methods (Kleinman, 2003). For instance screening tools should be culturally acceptable and user friendly for LHWs without compromising on sensitivity and specificity (Akena et al. 2012b). In this regard, several tools when translated into African languages and validated against recognised gold standards have been found to be appropriate for use in Africa, such as the SRQ-20, GHQ-12, the HADS-D and PHQ-9 (Ali et al. 2016). In addition, there is 
emerging evidence of validated visual tools for illiterate populations (Akena et al. 2012a).

During the formative phase of the Friendship Bench (Chibanda et al. 2016b), LHWs were involved in the validation of screening tools. This exercise included translation/back-translation of tools, reviewing the gold standard, protocol training and deciding on a cutoff score based on sensitivity and specificity. We have found that LHW involvement in what is traditionally perceived to be technical work is critical for enhanced buy-in and likelihood of continued use of validated screening tools by LHWs after the study period.

Second, during the development of the psychological intervention, LHW participation contributed to the team's understanding of local concepts of $\mathrm{CMD}$, including indigenous idioms of distress used to navigate through the therapy sessions (Chibanda et al. 2016a). For instance, locally conceived terms for PST such as kuvhura pfungwa (opening the mind through empathy and listening), kusimudzira (uplifting through acknowledging the problems and facilitating a process aimed at selecting a single problem to focus on) and kusimbisa (strengthening through the process of brain storming for solutions) contributed towards the development of a local mental health lexicon and cultivated community ownership of the intervention (Chibanda et al. 2016a). The final intervention, which was tested through a cluster randomised controlled trial (Chibanda et al. 2015a) showed effectiveness of all outcome measures after a 6-month follow-up (submitted). The clinical trial findings prompted the health authorities to recommend scaling up of the Friendship Bench (Chibanda et al. 2016d).

\section{Government endorsed scale up}

A common challenge facing MNS researchers is how to integrate or scale up interventions that are effective (Eaton et al. 2011; Shidhaye et al. 2015). Using task shifting, promoting community-based recovery, and use of training as a continuous way of strengthening clinical competencies are some suggested strategies for integrating and sustaining MNS care in primary care settings (Patel et al. 2010; Ventevogel, 2014).

Political buy-in has been described as an equally important component of the process (Collins et al. 2013; Rebello et al. 2014). In Zimbabwe, political buy-in for the scaling up of the Friendship bench to over 70 primary health care clinics has largely been driven by local health authorities and the community (Chibanda et al. 2016d). Three key-selling points aimed at achieving the above have been: (i) Emphasis on the added value of treating CMD as a comorbid condition in existing priority public health programmes such as HIV/AIDS, maternal and child health, and other
NCDs; (ii) an emphasis on using existing resources; and (iii) the novelty of providing therapy in an outdoor setting on a bench - the Friendship Bench (Chibanda et al. 2011), thus allowing for ease of access and scale up.

Over a 6-year period these three selling points have been highlighted, particularly during formal and informal meetings with both communities and policymakers.

Policymakers have regularly been invited as speakers or participants where these selling points have been emphasised. Furthermore, beneficiaries of the Friendship Bench intervention with co-morbid conditions such as HIV, hypertension, diabetes have been invited to speak about their experience of receiving care through the Friendship Bench and how this has helped address challenges related to their non-mental health co-morbid medical conditions. In addition, through this approach, partnerships aimed at strengthening both MNS and other priority public health conditions such as HIV/AIDS have been formed with Médecins sans Frontières (MSF) resulting in a winwin situation (Chibanda et al. 2016d).

While the strategies described above have shown positive results at national level, the foundation for these successes has been built through a number of earlier programmes. These include the US Government's Medical Educational partnership Initiative (MEPI) linked award for Improving Mental Health Education and Research in Zimbabwe (http://www.nectar-uz.ac. zw/IMHERZ), which contributed to the establishment of an academic and research development plan for the country. And recently the African Mental Health Research Initiative (AMARI) grant awarded by the Wellcome Trust as part of its DELTAS scheme which aims to Develop Excellence In Leadership Training And Science. Prior to this the Grand Challenges Canada (GCC) transition to scale grant (0763-05) had provided the platform for the scale up. These and other grants have deliberately been designed to integrate MNS care within existing health services with support from the government, particularly through salaries for LHWs and their immediate supervisors.

\section{Challenges}

Measuring fidelity of over 300 LHWs delivering the Friendship Bench intervention in over 70 primary care clinics has particularly been a major challenge. The use of mobile phone technology as described in the original Friendship Bench trial protocol (Chibanda et al. 2015a) has mitigated communication challenges between LHWs and their supervisors. With a $90 \%$ national mobile phone coverage the use of platforms such as SMS, WhatsApp and Slack have enabled regular fidelity checks, however, the reliability, sustainability and ethical implications of such platforms in the long term will need further research. 
LHWs on the Friendship Bench are predominantly trained in screening and managing common mental disorders such as depression and anxiety disorders among adults. However, care packages focusing on children and adolescents are urgently needed because most MNS begin during this period (Patel et al. 2007). Furthermore, other prevalent conditions such as substance use disorders and post-traumatic stress disorders will need to be integrated in the existing care package. How these additional components will impact on the current Friendship Bench structures is not known.

In recent years, a strategy that has been explored as a means of addressing these challenges is the common elements treatment approach (CETA) (Murray et al. 2014; Murray \& Jordans, 2016; Pacichana-Quinayaz et al. 2016). The CETA method relies on an internal stepped care approach (Murray et al. 2011), where LHWs are trained in the common elements care of several MNS, which then enables them to switch from one condition to the next based on presentation (Murray et al. 2014). However, such an approach may require a lot more training, support and supervision of LHWs and their immediate supervisors.

Finally, social-economic and political instabilities are often the main obstacle to implementing health programmes in Africa and Zimbabwe is no exception. Although salary support of LHWs and their supervisors throughout the country has contributed to the programme's success, a key mitigating factor to the country's social-economic and political volatility has been the strong focus on making the community the key driving force behind the Friendship Bench.

\section{Conclusion}

Reducing the treatment gap for MNS in Africa cannot be viewed in isolation of other existing health challenges. There is need for MNS researchers to articulate the added value of including MNS care packages to existing programmes such as HIV/AIDS and maternal and child health care. Utilising existing resources is particularly important while understanding community needs and stakeholder perception will enhance likelihood of scale-up success.

Sustaining the current exponential growth of the Friendship Bench is likely to depend on how well the programme continues to leverage existing resources in public health and information and technology services. For instance, the mobile phone industry as a resource could facilitate training, supervision, data collection and real time interaction between LHW and client through virtual platforms.

With an estimated one billion mobile phones on the continent, our ability to significantly reduce the treatment gap for MNS may in the near future depend on how we leverage Africa's mobile phone platform.

\section{Acknowledgements}

The author would like to thank the entire Friendship Bench team for their support in gathering information leading to this paper.

\section{Financial Support}

The author is supported by a Grand Challenges Canada grant (MH0763-05), and a Wellcome Trust (DELTAS) grant - AMARI.

\section{Conflict of Interest}

None.

\section{References}

Akena D, Joska J, Musisi S, Stein DJ (2012a). Sensitivity and specificity of a visual depression screening instrument among HIV-positive individuals in Uganda, an area with low literacy. AIDS Behavior 16, 2399-2406.

Akena D, Joska J, Obuku EA, Amos T, Musisi S, Stein DJ (2012b). Comparing the accuracy of brief versus long depression screening instruments which have been validated in low and middle income countries: a systematic review. BMC Psychiatry 12, 187.

Ali GC, Ryan G, De Silva MJ (2016). Validated screening tools for common mental disorders in low and middle income countries: a systematic review. PLOS ONE 11, e0156939.

Bolton P, Bass J, Neugebauer R, Verdeli H, Clougherty KF, Wickramaratne P, Speelman L, Ndogoni L, Weissman M (2003). Group interpersonal psychotherapy for depression in rural Uganda: a randomized controlled trial. Journal of the American Medical Association 289, 3117.

Breuer E, Lee L, De Silva M, Lund C (2016). Using theory of change to design and evaluate public health interventions: a systematic review. Implementation Science 11, 63.

Chibanda D, Mesu P, Kajawu L, Cowan F, Araya R, Abas M (2011). Problem-solving therapy for depression and common mental disorders in Zimbabwe: piloting a task-shifting primary mental health care intervention in a population with a high prevalence of people living with HIV. BMC Public Health 11, 828.

Chibanda D, Benjamin L, Weiss HA, Abas M (2014a). Mental, neurological, and substance use disorders in people living with HIV/AIDS in low- and middle-income countries. Journal of Acquired Immune Deficiency Syndromes 67 (Suppl. 1), S54-S67.

Chibanda D, Shetty AK, Tshimanga M, Woelk G, Stranix-Chibanda L, Rusakaniko S (2014b). Group problem-solving therapy for postnatal depression among HIV-positive and HIV-negative mothers in Zimbabwe. 
Journal of the International Association of Providers of AIDS Care 13, 335-341.

Chibanda D, Bowers T, Verhey R, Rusakaniko S, Abas M, Weiss HA, Araya R (2015a). The Friendship Bench programme: a cluster randomised controlled trial of a brief psychological intervention for common mental disorders delivered by lay health workers in Zimbabwe. International Journal of Mental Health Systems 9, 21.

Chibanda D, Cowan FM, Healy JL, Abas M, Lund C (2015b). Psychological interventions for common mental disorders for people living with HIV in low- and middle-income countries: systematic review. Tropical Medicine $\mathcal{E}$ International Health 20, 830-839.

Chibanda D, Cowan F, Verhey R, Machando D, Abas M, Lund C (2016a). Lay health workers' experience of delivering a problem solving therapy intervention for common mental disorders among people living with HIV: a qualitative study from Zimbabwe. Community Mental Health Journal. doi: 10.1007/s10597-016-0018-2.

Chibanda D, Verhey R, Gibson LJ, Munetsi E, Machando D, Rusakaniko S, Munjoma R, Araya R, Weiss HA, Abas M (2016b). Validation of screening tools for depression and anxiety disorders in a primary care population with high HIV prevalence in Zimbabwe. Journal of Affective Disorders 198, 50-55.

Chibanda D, Verhey R, Munetsi E, Cowan FM, Lund C (2016c). Using a theory driven approach to develop and evaluate a complex mental health intervention: the friendship bench project in Zimbabwe. International Journal of Mental Health Systems 10, 16.

Chibanda D, Verhey R, Munetsi E, Rusakaniko S, Cowan F, Lund C (2016d). Scaling up interventions for depression in sub-Saharan Africa: lessons from Zimbabwe. Global Mental Health 3, e13 (9 pages).

Collins PY, Insel TR, Chockalingam A, Daar A, Maddox YT (2013). Grand challenges in global mental health: integration in research, policy, and practice. PLoS Medicine 10, e1001434.

Cooper P, Landman M, Tomlinson M, Molteno C, Swartz L, Murray L (2002a). The impact of mother-infant intervention in an indigent per-urban South African context: a pilot study. British Journal of Psychiatry 180, 76.

Cooper PJ, Landman M, Tomlinson M, Molteno C, Swartz L, Murray L, Cooper PJ, Landman M, Tomlinson M, Molteno C, Swartz L, Murray L (2002b). Impact of a mother-infant intervention in an indigent peri-urban South African context: pilot study. British Journal of Psychiatry 180, 76-81.

De Silva MJ, Breuer E, Lee L, Asher L, Chowdhary N, Lund C, Patel V (2014). Theory of change: a theory-driven approach to enhance the Medical Research Council's framework for complex interventions. Trials 15, 267.

Dudo A, Besley JC (2016). Scientists' prioritization of communication objectives for public engagement. PLoS ONE 11, e0148867.

Eaton J, McCay L, Semrau M, Chatterjee S, Baingana F, Araya R, Ntulo C, Thornicroft G, Saxena S (2011). Scale up of services for mental health in low-income and middle-income countries. Lancet 378, 1592-1603.

Gureje O, Alem A (2000). Mental health policy development in Africa. International Journal of Public Health 78, 475.
Hailemariam M, Fekadu A, Selamu M, Alem A, Medhin G, Giorgis TW, DeSilva M, Breuer E (2015). Developing a mental health care plan in a low resource setting: the theory of change approach. BMC Health Service Research 15, 429 .

Kaaya S, Eustache E, Lapidos-Salaiz I, Musisi S, Psaros C, Wissow L (2013a). Grand challenges: improving HIV treatment outcomes by integrating interventions for co-morbid mental illness. PLoS Medicine 10, e1001447.

Kaaya SF, Blander J, Antelman G, Cyprian F, Emmons KM, Matsumoto K, Chopyak E, Levine M, Smith Fawzi MC (2013b). Randomized controlled trial evaluating the effect of an interactive group counseling intervention for HIV-positive women on prenatal depression and disclosure of HIV status. AIDS Care 25, 854-862.

Kleinman A (2003). Special section on cross-cultural psychiatry, introduction: common mental disorders, primary care, and the global mental health research agenda. Harvard Review of Psychiatry 11, 155.

Kohn R, Saxena S, Levav I, Saraceno B, Kohn R, Saxena S, Levav I, Saraceno B (2004). The treatment gap in mental health care. Bulletin of the World Health Organization 82, 858-866.

Lund C, Alem A, Schneider M, Hanlon C, Ahrens J, Bandawe C, Bass J, Bhana A, Burns J, Chibanda D, Cowan F, Davies T, Dewey M, Fekadu A, Freeman M, Honikman S, Joska J, Kagee A, Mayston R, Medhin G, Musisi S, Myer L, Ntulo T, Nyatsanza M, Ofori-Atta A, Petersen I, Phakathi S, Prince M, Shibre T, Stein DJ, Swartz L, Thornicroft G, Tomlinson M, Wissow L, Susser E (2015). Generating evidence to narrow the treatment gap for mental disorders in sub-Saharan Africa: rationale, overview and methods of AFFIRM. Epidemiology $\mathcal{E}$ Psychiatric Sciences 24, 233-240.

Mokdad AH, Forouzanfar MH, Daoud F, Mokdad AA, El Bcheraoui C, Moradi-Lakeh M, Kyu HH, Barber RM, Wagner J, Cercy K, Kravitz H, Coggeshall M, Chew A, O'Rourke KF, Steiner C, Tuffaha M, Charara R, Al-Ghamdi EA, Adi Y, Afifi RA, Alahmadi H, AlBuhairan F, Allen N, AlMazroa M, Al-Nehmi AA, AlRayess Z, Arora M, Azzopardi P, Barroso C, Basulaiman M, Bhutta ZA, Bonell C, Breinbauer C, Degenhardt L, Denno D, Fang J, Fatusi A, Feigl AB, Kakuma R, Karam N, Kennedy E, Khoja TA, Maalouf F, Obermeyer CM, Mattoo A, McGovern T, Memish ZA, Mensah GA, Patel V, Petroni S, Reavley N, Zertuche DR, Saeedi M, Santelli J, Sawyer SM, Ssewamala F, Taiwo K, Tantawy M, Viner RM, Waldfogel J, Zuniga MP, Naghavi M, Wang H, Vos T, Lopez AD, Al Rabeeah AA, Patton GC, Murray CJ (2016). Global burden of diseases, injuries, and risk factors for young people's health during 1990-2013: a systematic analysis for the Global Burden of Disease Study 2013. Lancet 387, 2383-2401.

Murray LK, Jordans MJ (2016). Rethinking the service delivery system of psychological interventions in low and middle income countries. BMC Psychiatry 16, 234.

Murray LK, Dorsey S, Bolton P, Jordans MJ, Rahman A, Bass J, Verdeli H (2011). Building capacity in mental health interventions in low resource countries: an apprenticeship model for training local providers. International Journal of Mental Health Systems 5, 30. 
Murray LK, Dorsey S, Haroz E, Lee C, Alsiary MM, Haydary A, Weiss WM, Bolton P (2014). A common elements treatment approach for adult mental health problems in low- and middle-income countries. Cognitive $\mathcal{E}$ Behavioral Practice 21, 111-123.

Musesengwa R, Chimbari MJ (2016). Community engagement practices in Southern Africa: review and thematic synthesis of studies done in Botswana, Zimbabwe and South Africa. Acta Tropica. doi: 10.1016/j.actatropica. 2016.03.021.

Mynors-Wallis L, Gath D, Lloyd-Thomas A, Tomlinson D (1995). Randomised controlled trial comparing problem solving treatment with amitriptyline and placebo for major depression in primary care. BMJ 310, 441-445.

Nakimuli-Mpungu E, Okello J, Kinyanda E, Alderman S, Nakku J, Alderman JS, Pavia A, Adaku A, Allden K, Musisi S (2013). The impact of group counseling on depression, post-traumatic stress and function outcomes: a prospective comparison study in the Peter C. Alderman trauma clinics in northern Uganda. Journal of Affective Disorders 151, 78-84.

Nakimuli-Mpungu E, Wamala K, Okello J, Alderman S, Odokonyero R, Mojtabai R, Mills EJ, Kanters S, Nachega JB, Musisi S (2015). Group support psychotherapy for depression treatment in people with HIV/AIDS in northern Uganda: a single-centre randomised controlled trial. Lancet HIV 2, e190-e199.

Olagunju AT, Ogundipe OA, Erinfolami AR, Akinbode AA, Adeyemi JD (2013). Toward the integration of comprehensive mental health services in HIV care: an assessment of psychiatric morbidity among HIV-positive individuals in sub-Saharan Africa. AIDS Care 25, 1193-1198.

Pacichana-Quinayaz SG, Osorio-Cuellar GV, Bonilla-Escobar FJ, Fandino-Losada A, Gutierrez-Martinez MI (2016). Common Elements Treatment Approach based on a Cognitive Behavioral Intervention: implementation in the Colombian Pacific. Ciencia Saude Coletiva 21, 1947-1956.

Patel V, Mann A (1997). Etic and emic criteria for non-psychotic mental disorder: a study of the CISR and care provider assessment in Harare. Social Psychiatry $\mathcal{E}$ Psychiatric Epidemiology 32, 84.

Patel V, Flisher AJ, Hetrick S, McGorry P (2007). Mental health of young people: a global public-health challenge. Lancet 369, 1302-1313.

Patel V, Maj M, Flisher AJ, De Silva MJ, Koschorke M, Prince M, Zonal WPA, Member Society R (2010).
Reducing the treatment gap for mental disorders: a WPA survey. World Psychiatry 9, 169-176.

Petersen I, Lund C, Stein DJ (2011). Optimizing mental health services in low-income and middle-income countries. Current Opinion in Psychiatry 24, 318.

Rahman A (2015). Integration of mental health into priority health service delivery platforms: maternal and child health services. Eastern Mediterranean Health Journal 21, 493-497.

Rebello TJ, Marques A, Gureje O, Pike KM (2014). Innovative strategies for closing the mental health treatment gap globally. Current Opinion Psychiatry 27, 308-314.

Sherr L, Clucas C, Harding R, Sibley E, Catalan J (2011). HIV and depression - a systematic review of interventions [Review]. Psychology Health \& Medicine 16, 493-527.

Shidhaye R, Lund C, Chisholm D (2015). Closing the treatment gap for mental, neurological and substance use disorders by strengthening existing health care platforms: strategies for delivery and integration of evidence-based interventions. International Journal of Mental Health Systems 9, 40 .

South J, Phillips G (2014). Evaluating community engagement as part of the public health system. Journal of Epidemiology \& Community Health 68, 692-696.

van Ginneken N, Tharyan P, Lewin S, Rao GN, Meera SM, Pian J, Chandrashekar S, Patel V (2013). Non-specialist health worker interventions for the care of mental, neurological and substance-abuse disorders in low- and middle-income countries. Cochrane Database System Review CD009149.

van't Hof E, Stein DJ, Marks I, Tomlinson M, Cuijpers P (2011). The effectiveness of problem solving therapy in deprived South African communities: results from a pilot study. BMC Psychiatry 11, 156.

Ventevogel P (2014). Integration of mental health into primary healthcare in low-income countries: avoiding medicalization. International Review of Psychiatry 26, 669-679.

Ventevogel P, de Jong JT (2006). The effectiveness of mental health care in developing countries. Intervention and policy options at several levels. Tijdschrift voor Psychiatrie 48, 283-293.

Verhey R, Chibanda D, Brakarsh J, Seedat S (2016). Psychological interventions for post-traumatic stress disorder in people living with HIV in Resource poor settings: a systematic review. Tropical Medicine $\mathcal{E}$ International Health 21, 1198-1208. 